\title{
Design of microstrip coupledline bandpass filter
}

\author{
Mubina Šašić ${ }^{1}$, Sehabbedin Taha Imeci ${ }^{{ }^{*}}$ \\ ${ }^{1}$ Electrical and Electronics Engineering, International University of Sarajevo, Bosnia
}

*Corresponding author: timeci@ius.edu.ba

(C) The Author(s)

2021.

Published by ARDA.

\begin{abstract}
This project contains basic information, design, 3D projection, simulation, and analysis of Microstrip Bandpass Filter. The filter was composed of the feed lines connected to the two ports with the parallel-coupled lines between them. The separation between these elements is reduced to the minimum for the purpose of reducing the error. Ultimately, the microstrip bandpass filter was designed with a $400 \mathrm{MHz}$ bandwidth. We end up with these results: at the $4.43 \mathrm{GHz}$, the $\mathrm{S} 11$ parameter is $-9.868 \mathrm{~dB}$ and $\mathrm{S} 22$ is $-1.808 \mathrm{~dB}$, while at the $4.83 \mathrm{GHz}, \mathrm{S} 11$ is $9.995 \mathrm{~dB}$ and $\mathrm{S} 22$ is $-1.826 \mathrm{~dB}$.
\end{abstract}

Keywords: Bandpass Filter (BPF), Coupled-line bandpass microstrip filter (CBMF), Microstrip, Return Loss, Chebyshev filter

\section{Introduction}

The filters can be considered as one of the crucial parts of the microwave system and any communication system. The types of filter that are used in these communication systems are classified as low-pass filter, highpass filter, band-pass filter, and band-stop filter [1]. Bandpass filter represents a passive component which has an ability to select signals inside a particular bandwidth at a certain frequency and reject signals in another frequency domain. The important roles in designing the bandpass filter are determining the maximal loss inside the pass domain, the minimal attenuation in the reject/stop domains and ensuring that the filter characteristics are like in transition domains [2].

Mostly, designing these filters is accomplished by using one or more resonators, coupled to each other. These resonator parts can be represented as physical components that store electric and magnetic energy in a frequency - dependent way. Typically, these filters are widely used in many communication systems such as satellite, mobile and radar.

For achieving good features of the filter, like high return loss and big rejection band levels, some parameters require more attention to be paid at, besides the compactness requirement.

There are several ways for reducing the size of the filter, for example, it can be realized from dielectric substrates with big magnitudes of dielectric constant, but since this is the microstrip filter design, preferred method should be changing the geometry of the filter, because the big dielectric constant material will cause further losses [3].

\section{Material and methods}

The proposed design of the microstrip bandpass is fabricated on FR-4 material with relative permittivity $\varepsilon r=$ 4.4 and the thickness $\mathrm{h}=1.55 \mathrm{~mm}$, while the characteristic impedance is chosen as $\mathrm{Z}_{0}=50 \Omega$. Using the principle of the parallel coupling, the final design is represented in Fig. 1. The unit of the dimensions is represented in milimeters. 


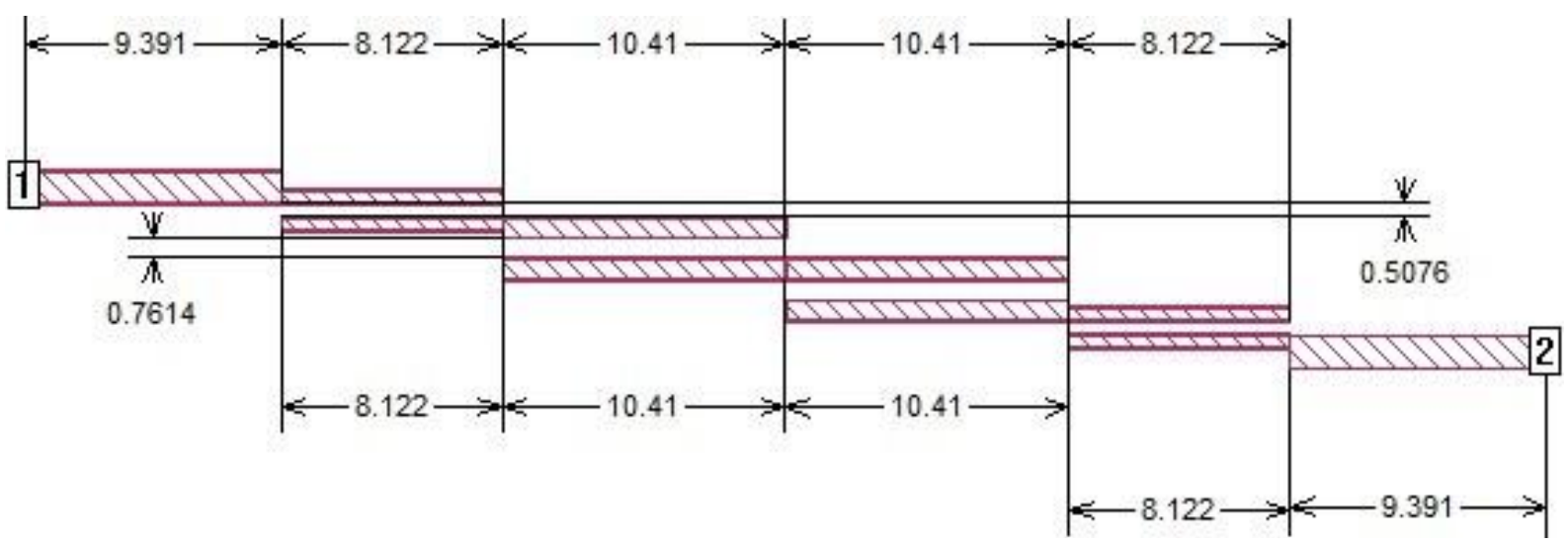

Figure 1. Top view of the filter

The 3D view of the proposed filter is shown in the Fig. 2. The top metal is free space, while the ground metal is lossless.

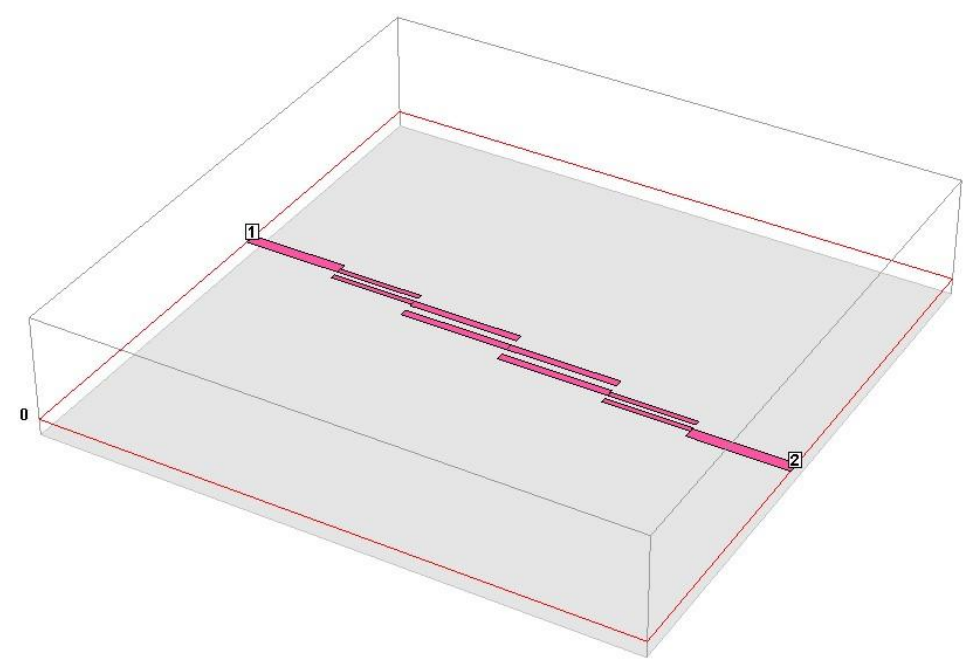

Figure 2. 3D view of the filter

Table 1. Microstrip filter dimensions

Element

Feedline

Coupled lines

Central Box
Length

$9.391 \mathrm{~mm}$

$8.122 \mathrm{~mm}$

$10.41 \mathrm{~mm}$
Width

$1.142 \mathrm{~mm}$

$0.5076 \mathrm{~mm}$

$0.7614 \mathrm{~mm}$

\section{Types of analog filters}

\subsection{Passive bandpass filter}

Bandpass filters are usually used for isolating or filtering out specific frequencies which are established in certain range or frequency band. That band or bandwidth represents the frequency range which lies between points that are $3 \mathrm{~dB}$ below the maximum center or resonant peak while attenuating or weakening the others outside of the range of these two points. To sum up, bandwidth is represented as the difference between the lower cut-off frequency $\left(f \mathrm{c}_{\mathrm{LOW}}\right)$ and the higher cut-off frequency $\left(f_{\mathrm{c}_{\mathrm{HIGH}}}\right)$ points (bandwidth $\left.=f_{\mathrm{H}}-f_{\mathrm{L}}\right)$. We need to pay attention that the cut-off frequency of the low pass filter must be higher than the cut-off frequency for the high pass filter. 


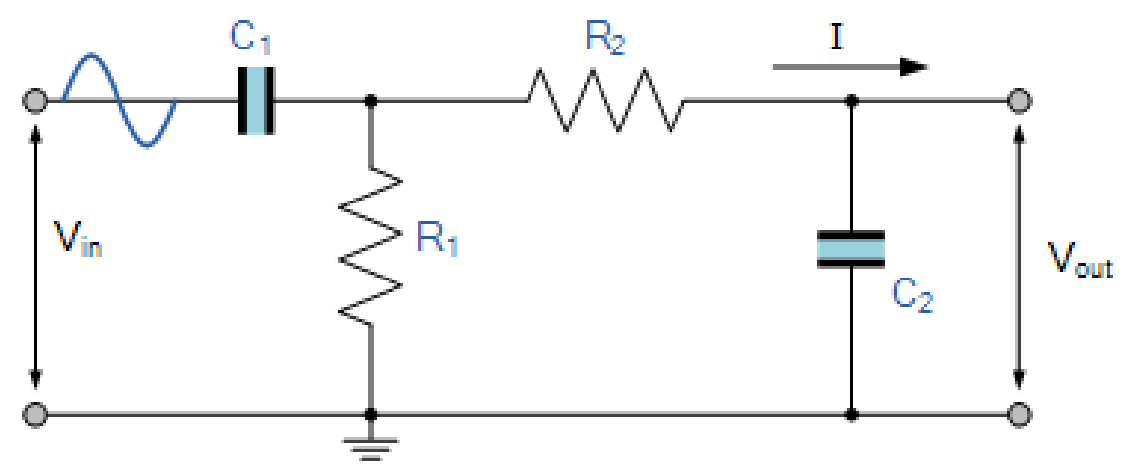

Figure 3. Passive bandpass filter [4]

One way of controlling the cut-off frequency in a passive filter can be done with a single resistor in series with a non-polarized capacitor and by the way of connecting a circuit of low pass and high pass filter circuit, it is possible to provide a different type of passive RC filter which passes a certain frequency bandwidth (narrow or wide) while all the other frequencies are being attenuated. In ideal cases, the working principle of bandpass filter can also be useful for noise cancellation. These filters are named as second order filters because of having two reactive components in their design. These components are the capacitors and one of them is placed in the low pass circuit while the other capacitor is placed in the high pass circuit [4].

\subsection{Active bandpass filter}

In order to achieve an active band pass filter, we should take into account that the band for low pass filter begins from $0 \mathrm{~Hz}$ and goes up to certain frequencies of half power amplitude point. At the same time, the band for a high pass filter also begins from the same point and goes up to the active filter's maximum open gain.

This filter is used to divide a signal at one certain frequency. It can be made by connecting a low pass filter and high pass filter like in the figure below:

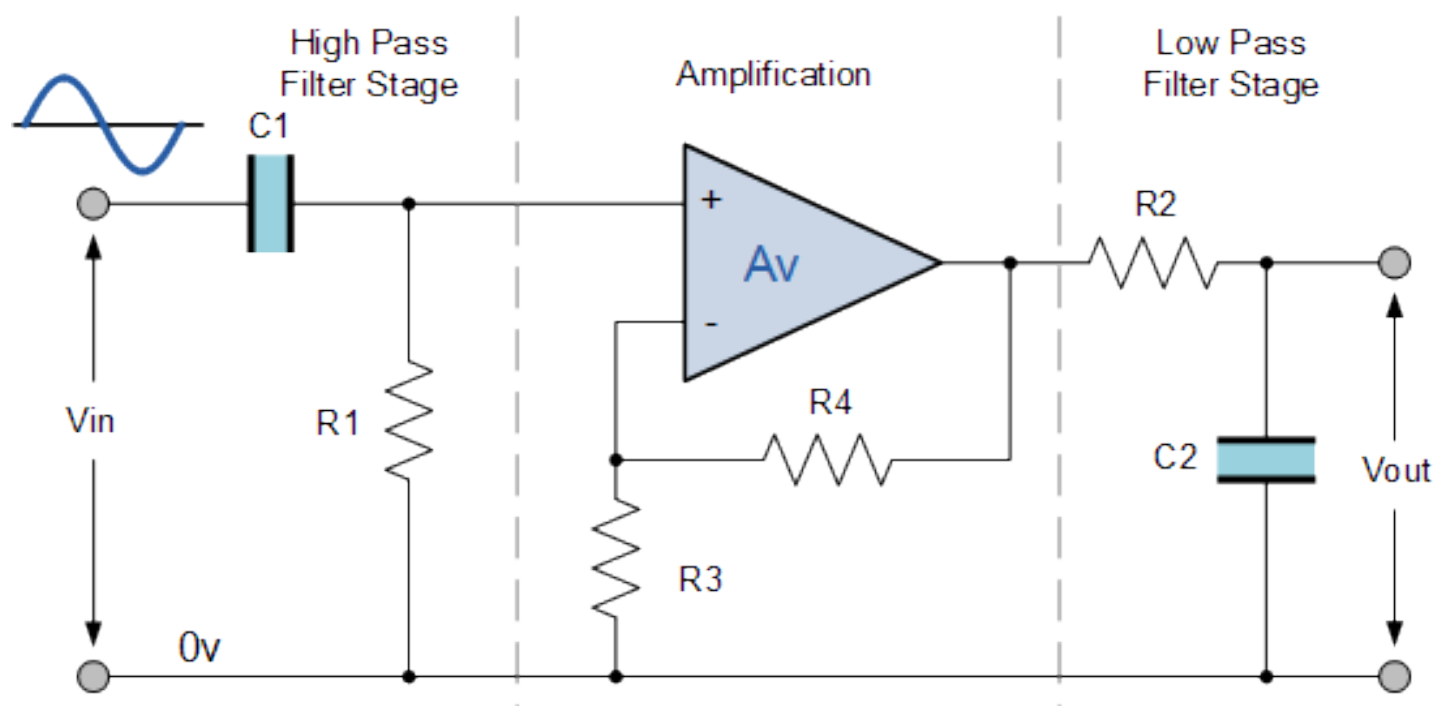

Figure 4. Active bandpass filter [5]

Gathering together the low and high pass filter circuits results in getting a Q - factor type filter circuit that has a wide band. The left side of the circuit represents high pass stage in which the capacitor blocks any kind of DC loading from the source. The advantage of this design technique is producing a quite flat asymmetrical pass band frequency response where the first half represents the low pass filter's response and the other half represents the high pass filter's response as shown in Fig. 5. 

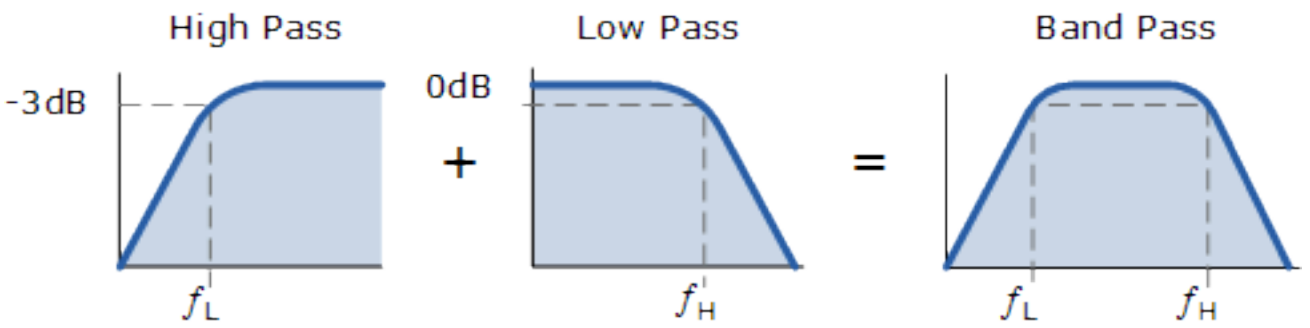

Figure 5. Modeling the bandpass filter [5]

\subsection{Butterworth filter}

The Butterworth Filter represents linear analogue filter where its approximation function has the response which is almost flat - it does not have any ripples. This is possible because this filter's pass band is designed in such way that the frequency response begins at $0 \mathrm{~Hz}$ and ends at the cut-off frequency, which is $-3 \mathrm{~dB}$, without any ripples. The quality factor of this filter is only 0.707 because the frequencies which are beyond the cut-off frequency points drops to zero in the stop band of $20 \mathrm{~dB}$, which is the reason of the slow response.

The main advantages of the Butterworth filter are that it creates the smoothest curve and every time we increase the order of the filter, it gets the steeper attenuation slope near the cut-off frequency. Nevertheless, the main disadvantages of this filter are that it has poor phase characteristics and when the filter makes the transition from the pass band to the stop band, it achieves the maximally flat band at the cost of a wide transition band. [5]

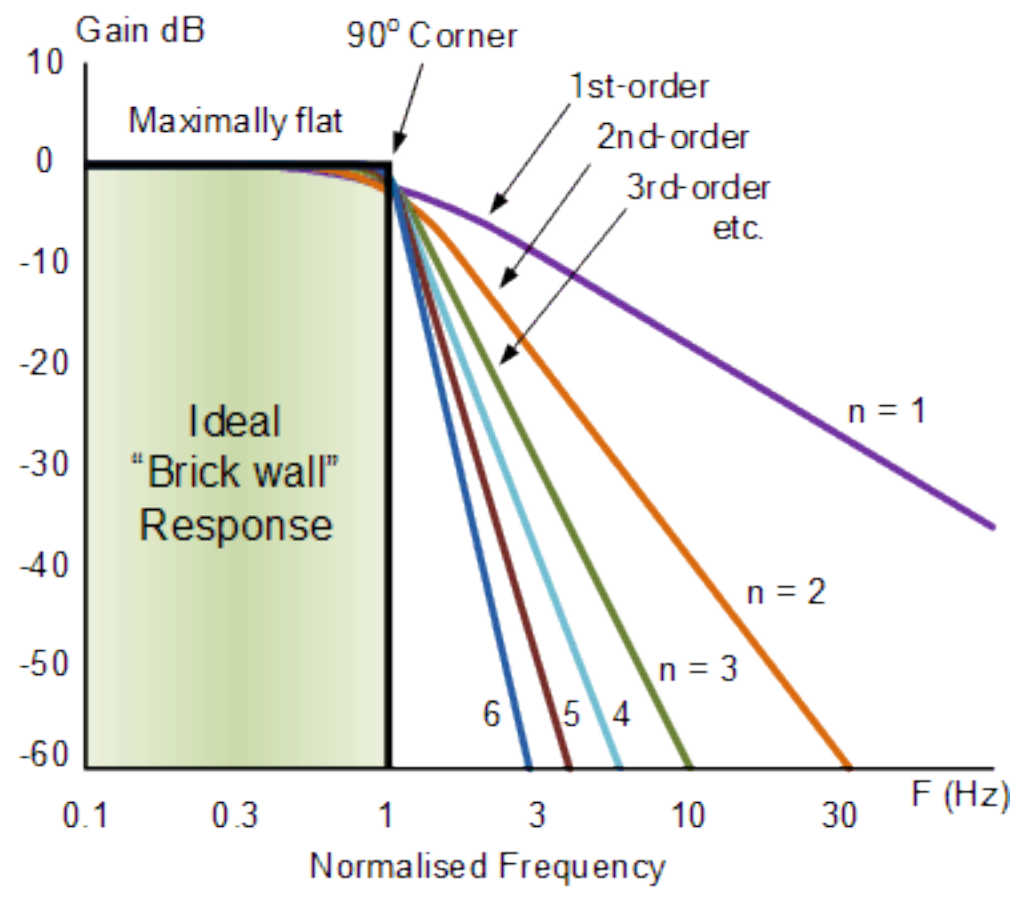

Figure 6. Butterworth filter's ideal response [6]

The figure above represents an ideal frequency response of the Butterworth filter and the standard appoximations for the different orders of the filter. We can relate this ideal response as a "brick wall" and in order to get closer to it, we should increase the Butterworth filter order, which also results in increasing the stages in the filter design. Unfortunately, reaching the ideal response is not possible in the practice.

The transfer function that represents the frequency response of the nth order of the Butterworth filter, can be written as below: 


$$
H=\frac{1}{\sqrt{1+\varepsilon^{2}\left(\frac{\omega}{\omega_{p}}\right)^{2 n}}}
$$

where:

$\varepsilon$ - electrical permeability

$\mathrm{n}$ - the filter order

$\omega=2 \pi f-$ angular frequency

$\mathrm{A}_{\max }$ - maximum pass band gain

In case that $\mathrm{A}_{\max }$ equals to $-3 \mathrm{~dB}$ cut-off corner point, then $\varepsilon$ equals to one. If we want to define maximum band pass gain at a different value, then we can find the $\varepsilon$ by solving the following equation:

$$
H_{1}=\frac{H_{0}}{\sqrt{1+\varepsilon^{2}}}
$$

where:

$\mathrm{H}_{0}$ - the maximum pass band gain, $\mathrm{A}_{\max }$

$\mathrm{H}_{1}$ - the minimum pass band gain

\subsection{Chebyshev filter}

The Chebyshev filter has an ability to reduce the error between the real filter and ideal filter's specifications. It is used for separating frequencies of one band from the other. The main advantage of this filter is its speed - it is faster than the Butterworth filter. Since this filter is not carried out by convolution, but the recursion, the design of the Chebyshev filter depends on the $\mathrm{Z}$ - transform. In order to design the Chebyshev filter, the circular pattern of the poles has to be transformed into an elliptical pattern. The relative flatness of the ellipse is the main indicator of how much ripple exists in the filter's pass band [7].

There are two types of the Chebyshev filters - type-I Chebyshev filter and type-II Chebyshev filter. What is our concern is type-I Chebyshev filter, because it is more efficient and common than the type-II which is also called the inverse filter.

In the type-I Chebyshev filter, the amplitude response is represented by an angular frequency function which is the nth order of the loss pass filter and equal to the $\mathrm{Hn}(\mathrm{jw})$ transfer function which can be observed in the following expression:

$$
G_{n}(\omega)=\left|H_{n}(\mathrm{j} \omega)\right|=\frac{1}{\sqrt{1+\varepsilon^{2} T_{n}^{2}\left(\frac{\omega}{\omega_{0}}\right)}}(3)
$$

where,

$\varepsilon$ - ripple factor

$\omega_{0}$ - cut-off frequency

$T_{n}-$ Chebyshev polynomial of the $\mathrm{n}^{\text {th }}$ order 


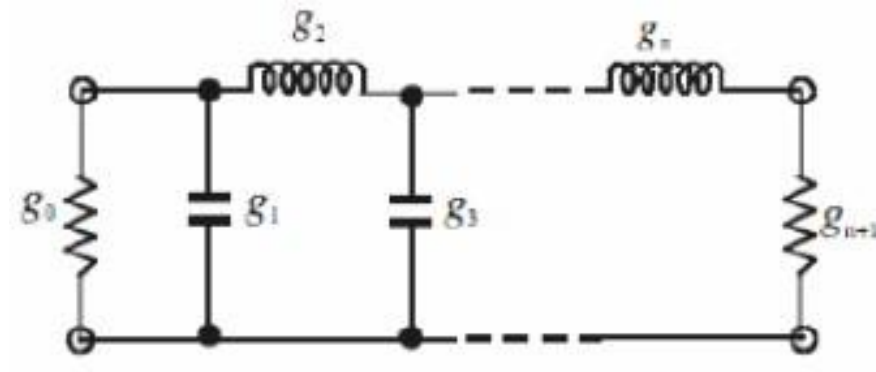

( $n$ even)

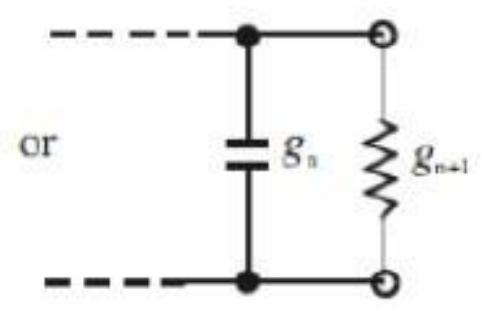

( $n$ odd)
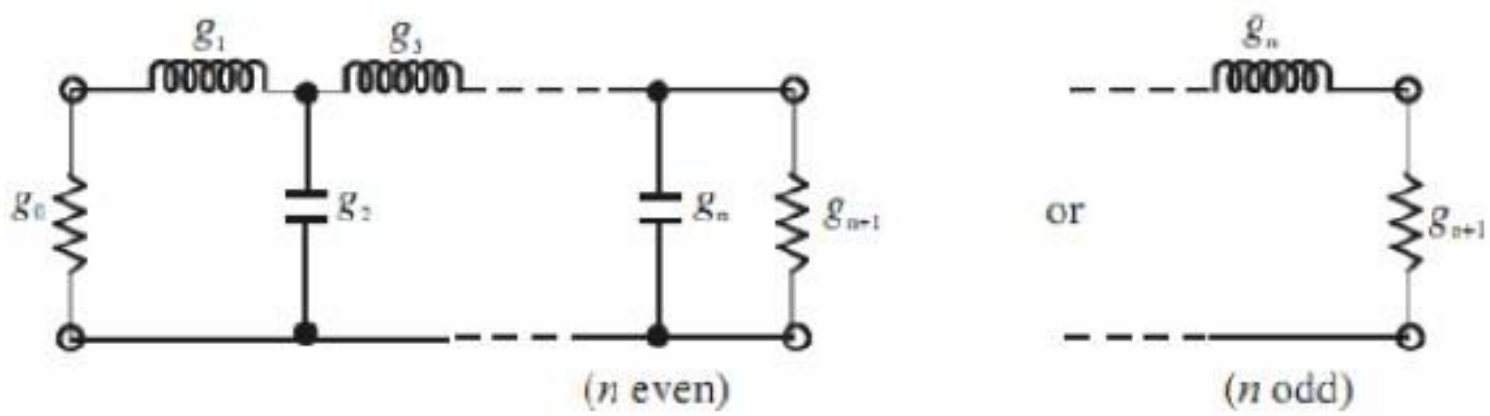

Figure 7. Filter's design using LC components [8]

The filter's gain is between $G=1$, which is maximum and minimum $G=\frac{1}{\sqrt{1+\varepsilon^{2}}}$, since this filter oscillates in the range of -1 and 1 . The gain has minimum value at the cut-off frequency and as the frequency increases, it keeps on failing into stop band.

Elliptic (Cauer) filter represents the effect that appears if the ripple is in the stop band, which causes steeper roll-off by permitting zero's in the complex plane on j $\omega$ - axis. In the figure, the ripple equals to $20 \log 10 \sqrt{1+\varepsilon^{2}} \mathrm{~dB}$, which means that the amplitude of $3 \mathrm{~dB}$ comes from $\varepsilon=1$.

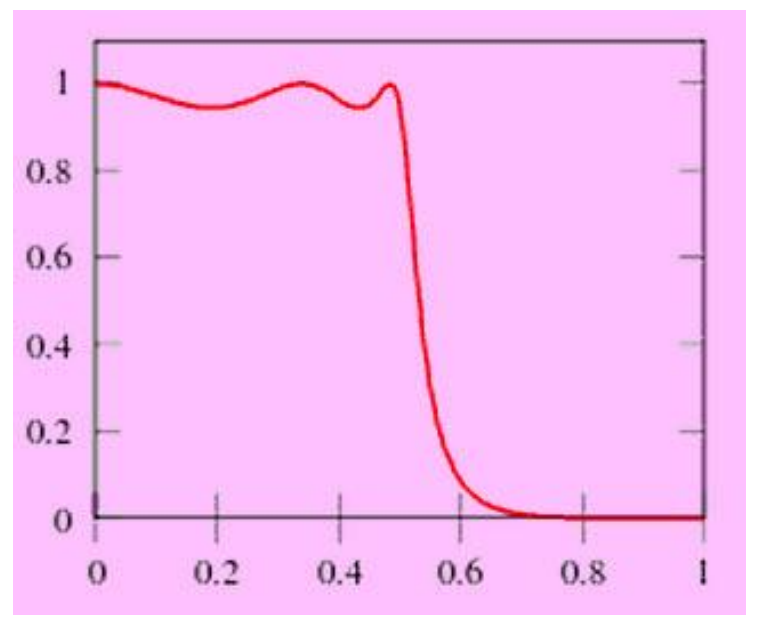

Figure 8. The behavior of type-I Chebyshev filter [7]

This filter also have the poles which can be defined by the gain of the filter. The transfer function is stable and represented as below:

$$
H(s)=\frac{1}{2^{n-1} \varepsilon} \prod_{m=1}^{n} \frac{1}{\left(s-s_{p m}^{-}\right)}
$$




\subsection{The microstrip technology}

Microstrip transmission line represents one of the most used transmission lines in microwave engineering applications. The biggest advantage of mictrostrip line is to have the circuit on the patch. One of the disadvantages when designing a filter with microstrip lines is appearance of external shielding due to high isolation which causes the radiation and sometimes unwanted filter's response. Even though mictrostrip supports TEM mode due to microstrip's filling factor, which represents a measure of percentage of the electric fields in a transmission line that cut through the substrate [2], sometimes microstrip can behave as non-TEM because of the coupled lines or even and odd modes. Because of this behavior, the frequency of the microstrip bandpass filter is asymmetric [9]. The dielectric constants are important in microstrip technology. The effective dielectric constant is less than substrate's dielectric constant due to the fact that some parts of the microstrip conductor's fields exist in the air. The effective dielectric constant of microstrip can be calculated as in the following:

$$
\text { Case 1: }\left(\frac{W}{H}\right)<1
$$

Then,

$$
\begin{gathered}
\varepsilon_{e}=\frac{\varepsilon_{r}+1}{2}+\frac{\varepsilon_{r}-1}{2}\left[\left(1+12\left(\frac{H}{W}\right)\right)^{-\frac{1}{2}}+0.04\left(1-\left(\frac{W}{H}\right)\right)^{2}\right] \\
\text { Case 2: }\left(\frac{W}{H}\right) \geq 1 \\
\varepsilon_{e}=\frac{\varepsilon_{r}+1}{2}+\frac{\varepsilon_{r}-1}{2}\left(1+12\left(\frac{H}{W}\right)\right)^{-\frac{1}{2}}
\end{gathered}
$$

where,

$\varepsilon_{e}$ - the effective dielectric constant

$\varepsilon_{r}$ - the relative dielectric constant

$\mathrm{H}$ - height $[\mathrm{mm}]$

W - width $[\mathrm{mm}]$

All of these expressions are approximate and do not take the strip thickness and frequency dispersion into the account, because their effects are small.

\section{Results}

In the following table, the change of S11 and S22 parameters depending on the width and the separation between coupled lines and in the central box can be observed. Changing the length and width of the feed lines led to getting different results of the $\mathrm{S}$ parameters. The top metal is lossless, except for the final result where the top metal is free space.

Table 1. Parametric study

\begin{tabular}{cccccc}
$\begin{array}{c}\text { Type of } \\
\text { element }\end{array}$ & $\begin{array}{c}\text { Separation } \\
{[\mathbf{m m}]}\end{array}$ & $\begin{array}{c}\text { Width } \\
{[\mathbf{m m}]}\end{array}$ & $\begin{array}{c}\text { Length } \\
{[\mathbf{m m}]}\end{array}$ & $\begin{array}{c}\text { S11 [dB]/ } \\
\mathbf{f}[\mathbf{G H z}]\end{array}$ & $\begin{array}{c}\text { S12 [dB]/ } \\
\mathbf{f}[\mathbf{G H z}]\end{array}$ \\
\hline $\begin{array}{c}\text { Coupled } \\
\text { lines }\end{array}$ & 0.5076 & 0.5076 & 9.391 & $-9.404 / 2.92$ & $-1.963 / 2.92$ \\
$\begin{array}{c}\text { Coupled } \\
\text { lines }\end{array}$ & 0.7615 & 0.5076 & 9.137 & $-9.966 / 2.94$ & $-1.667 / 2.94$ \\
$\begin{array}{c}\text { Coupled } \\
\text { lines }\end{array}$ & 0.5076 & 0.5076 & 8.122 & $-9.868 / 4.43$ & $-1.808 / 4.43$ \\
$\begin{array}{c}\text { Central } \\
\text { Box }\end{array}$ & 2.284 & 0.7614 & 9.137 & $-9.407 / 2.94$ & $-1.955 / 2.94$ \\
\hline
\end{tabular}




\begin{tabular}{cccccc}
$\begin{array}{c}\text { Type of } \\
\text { element }\end{array}$ & $\begin{array}{c}\text { Separation } \\
{[\mathbf{m m}]}\end{array}$ & $\begin{array}{c}\text { Width } \\
{[\mathbf{m m}]}\end{array}$ & $\begin{array}{c}\text { Length } \\
{[\mathbf{m m}]}\end{array}$ & $\begin{array}{c}\text { S11 [dB]/ } \\
\mathbf{f}[\mathbf{G H z}]\end{array}$ & $\begin{array}{c}\text { S12 [dB]/ } \\
\mathbf{f}[\mathbf{G H z}]\end{array}$ \\
\hline $\begin{array}{c}\text { Central } \\
\text { Box }\end{array}$ & 1.269 & 0.7614 & 9.391 & $-9.966 / 2.94$ & $-1.667 / 2.94$ \\
$\begin{array}{c}\text { Central } \\
\text { Box }\end{array}$ & 0.5075 & 0.7614 & 10.41 & $-9.868 / 4.43$ & $-1.808 / 4.43$ \\
$\begin{array}{c}\text { Feed } \\
\text { lines }\end{array}$ & - & 0.7614 & 9.136 & $-9.966 /$ & $-1.667 / 2.94$ \\
$\begin{array}{l}\text { Feed } \\
\text { lines }\end{array}$ & - & 1.142 & 9.4 & $-8.302 / 4.49$ & $-5.193 / 4.49$ \\
$\begin{array}{l}\text { Feed } \\
\text { lines }\end{array}$ & - & 1.142 & 9.391 & $-9.868 / 4.43$ & $-1.808 / 4.43$ \\
\hline
\end{tabular}

The result is represented between $4 \mathrm{GHz}$ and $5 \mathrm{GHz}$ which can be seen in the Fig. 9. Reducing the separation between the coupled lines and in the central box led to the wider frequency bandwidth and better result of the return loss.

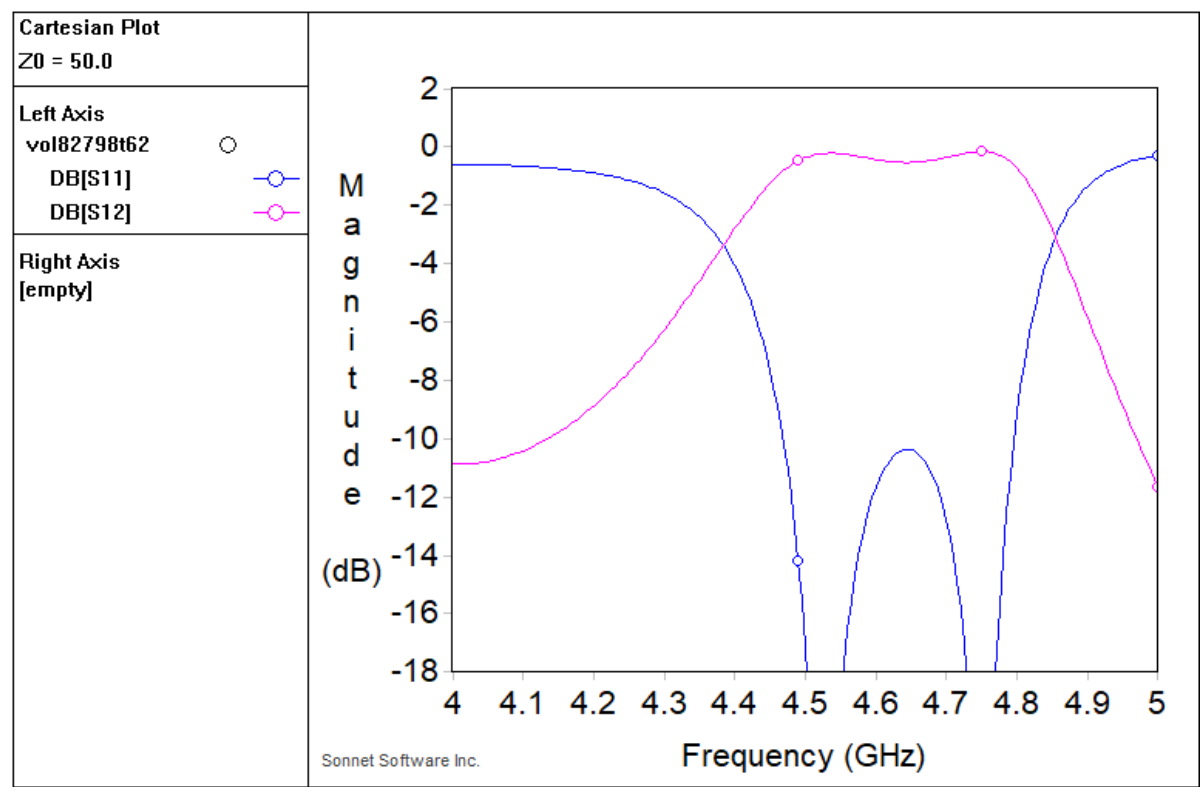

Figure 9. Simulation results

The ideal solution for this filter is achieving these results for S11 and S22 parameters in the $400 \mathrm{MHz}$ frequency bandwidth which can be represented as in the table below:

Table 3. The final results

\begin{tabular}{ccc}
$\begin{array}{c}\text { Frequency } \\
{[\mathbf{G H z}]}\end{array}$ & $\begin{array}{c}\text { S11 } \\
{[\mathbf{d B}]}\end{array}$ & $\begin{array}{c}\text { S12 } \\
{[\mathbf{d B}]}\end{array}$ \\
\hline $\mathbf{4 . 4 3}$ & -9.868 & -1.808 \\
& & \\
$\mathbf{4 . 8 3}$ & -9.995 & -1.826 \\
\hline
\end{tabular}

\section{Conclusion}

By comparing the tables, it can be observed that making the small changes in the dimensions can result the big difference in the frequency bandwidth and in the $\mathrm{S}$ parameters. That means, this filter is very sensitive to the size reduction. It is quite challenging to fabricate this type of filter due to the errors realized for the random factors and other parameters that have not been taken into the account [10]. Next steps which need to be taken 
is designing microstrip bandpass filter with the frequency bandwidth which is wider than $400 \mathrm{MHz}$. This research provided us good base for future work which can be accomplished by including the Chebyshev approach with the components like capacitors and inductors in the combination of other methods for realizing the filter with the better features. [11] The design of this microstrip bandpass filter has provided us acceptable simulations results with the frequency bandwidth of $400 \mathrm{MHz}$ realized in Sonnet Suite Software [12].

\section{References}

[1] R. N. Kadam and A.B. Nandgaonkar, "Design of a Coupled-Line Microstrip Bandpass Filter at 3.5 GHz", International Research Journal of Engineering and Technology (IRJET), vol. 2, pp. 1174, September 2015.

[2] M. Alaydrus, "Designing Microstrip Bandpass Filter at $3.2 \mathrm{GHz}$ ”, International Journal on Electrical Engineering and Informatics, vol. 2, no. 2, pp. 71-72, June 2010.

[3] Y. S. Mezaal and J. K. Ali, "Mezaal YS, Ali JK (2016) Investigation of Dual-Mode Microstrip Bandpass Filter Based on SIR Technique", PLoS one: e0164916, doi: 10.1371/journal.pone.0164916, pp. 1-3, October 2016.

[4] United States of America, AspenCore Inc: Passive Bandpass Filter. Retrieved from: https://www.electronics-tutorials.ws/filter/filter_4.html

[5] United States of America, AspenCore Inc: Active Bandpass Filter. Retrieved from: https://www.electronics-tutorials.ws/filter/filter_7.html

[6] United States of America, AspenCore Inc: Butterworth Filter. Retrieved from: https://www.electronicstutorials.ws/filter/filter_8.html

[7] United States of America, Elprocus: Chebyshev Filter. Retrieved from: https://www.elprocus.com/typesof-chebyshev-filters/

[8] P. Rani, S. Gupta and R. K. Prasad, "Design \& Optimization of Microstrip Parallel Coupled Bandpass Bandpass Filter at $20 \mathrm{GHz",} \mathrm{International} \mathrm{Journal} \mathrm{of} \mathrm{Advanced} \mathrm{Research} \mathrm{in} \mathrm{Computer} \mathrm{Engineering} \mathrm{\&}$ Technology (IJARCET), vol. 3, no. 5, May 2014.

[9] I. J. Bahl and D. K. Trivedi, "A Designer's Guide to Microstrip Line", Microwaves, pp. 174- 182, May 1977.

[10] A. R. Othman and C. Wasli, “2.4 GHz Microstrip Bandpass Filter”, Reach 2006, Penand, Malaysia pp.4.

[11] R. Taoufik and N. A. Touhami, "Designing a Microstrip coupled line bandpass filter", International Journal of Engineering \& Technology, DOI: 10.14419/IJet.v214.1173, pp. 268-269, 2013.

[12] Sonnet Suites, www.sonnetsoftware.com, ver. 17.52, Syracuse, NY, 2020

\section{Acknowledgements}

Realizing this project and the other application of the Microwave Engineering course has been possible thanks to the professor Sehabbedin Taha Imeci and the International University of Sarajevo which provided us student licences of the Sonnet Suite Software as well as giving us permission to take part in the fabrication of these filters in the Research Development Center of the International University of Sarajevo. 